\title{
Early diffusion-weighted MRI lesions after treatment of unruptured intracranial aneurysms: a prospective study
}

\author{
*Johannes Platz, MD, ${ }^{1}$ Marlies Wagner, MD, PhD, ${ }^{2}$ Erdem Güresir, MD, PhD, \\ Se-Jong You, MD, ${ }^{2}$ Juergen Konczalla, MD, ${ }^{1}$ Richard du Mesnil de Rochemont, MD, PhD, ${ }^{2}$ \\ Joachim Berkefeld, MD, PhD, ${ }^{2}$ and Volker Seifert, MD, PhD'1
}

Departments of ${ }^{1}$ Neurosurgery and ${ }^{2}$ Neuroradiology, University Hospital Frankfurt, Goethe-University, Frankfurt, Germany

\begin{abstract}
OBJECTIVE Diffusion-weighted MRI was used to assess periprocedural lesion load after repair of unruptured intracranial aneurysms (UIA) by microsurgical clipping (MC) and endovascular coiling (EC).

METHODS Patients with UIA were assigned to undergo MC or EC according to interdisciplinary consensus and underwent diffusion-weighted imaging (DWI) 1 day before and 1 day after aneurysm treatment. Newly detected lesions by DWI after treatment were the primary end point of this prospective study. Lesions detected by DWI were categorized as follows: A) 1-3 DWI spots $<10 \mathrm{~mm}, \mathrm{~B})>3$ DWI spots $<10 \mathrm{~mm}$, C) single DWI lesion $>10 \mathrm{~mm}$, or D) DWI lesion related to surgical access.
\end{abstract}

RESULTS Between 2010 and 2014, 99 cases were included. Sixty-two UIA were treated by MC and 37 by EC. There were no significant differences between groups in age, sex, aneurysm size, occurrence of multiple aneurysms in 1 patient, or presence of lesions detected by DWI before treatment. Aneurysms treated by EC were significantly more often located in the posterior circulation ( $p<0.001)$. Diffusion-weighted MRI detected new lesions in $27(43.5 \%)$ and 20 $(54.1 \%)$ patients after $\mathrm{MC}$ and EC, respectively (not significant). The pattern of lesions detected by DWI varied significantly between groups $(p<0.001)$. Microembolic lesions $(A$ and $B)$ found on DWI were detected more frequently after EC (A, 14 cases; B, 5 cases) than after MC (A, 5 cases), whereas $C$ and D were rare after EC (C, 1 case) and occurred more often after $M C$ (C, 12 cases and $D, 10$ cases). No procedure-related unfavorable outcomes were detected.

CONCLUSIONS According to the specific techniques, lesion patterns differ between $M C$ and $E C$, whereas the frequency of new lesions found on DWI is similar after occlusion of UIA. In general, the lesion load was low in both groups, and lesions were clinically silent.

Clinical trial registration no.: NCT01490463 (clinicaltrials.gov)

https://thejns.org/doi/abs/10.3171/2016.2.JNS152456

KEY WORDS cerebrovascular disease; observational study; MRI; magnetic resonance imaging; unruptured intracranial aneurysm; coiling; clipping; vascular disorders

$\mathrm{T}$ oDAY, microsurgical clipping (MC) and endovascular coiling (EC) are highly developed and wellestablished modalities for prophylactic treatment of unruptured intracranial aneurysms (UIA). Microsurgical clipping and EC differ in the degree of invasiveness and may also show differences regarding typical complications or long-term efficacy.
Centers offering both types of treatment have to find a consensus on the optimal kind of UIA treatment for each patient based on careful risk-benefit analyses and the patient's preferences. A description of typical complications is mandatory for proper counseling of patients. Ischemic events present the most important complication of both methods, with an immediate impact on the patient in cases

ABBREVIATIONS $A C A=$ anterior cerebral artery; $\mathrm{ACOA}=$ anterior communicating artery; $\mathrm{DSA}=$ digital subtraction angiography; $\mathrm{DWI}=$ diffusion-weighted imaging; $\mathrm{EC}=$ endovascular coiling; ICA = internal carotid artery; $M C=$ microsurgical clipping; $M C A=$ middle cerebral artery; $m R S=$ modified Rankin Scale; $P C o A=$ posterior communicating artery; PICA = posterior inferior cerebellar artery; UIA = unruptured intracranial aneurysms.

SUBMITTED October 22, 2015. ACCEPTED February 11, 2016.

INCLUDE WHEN CITING Published online May 20, 2016; DOI: 10.3171/2016.2.JNS152456.

* Drs. Platz and Wagner contributed equally to this work. 
TABLE 1. Published studies on the frequency of DWI-detected lesions after endovascular treatment of cerebral aneurysms

\begin{tabular}{|c|c|c|c|c|}
\hline Authors \& Year & No. of Cases & Presentation of Aneurysm & $\%$ Cases w/ DWI-Detected Lesions & $\%$ Symptomatic Patients \\
\hline \multirow[t]{2}{*}{ Altay et al., 2011} & 133 & UIA & 30 & 4.9 (overall) \\
\hline & 65 & Ruptured & 65 & \\
\hline Biondi et al., 2000 & 20 & Both & 10 & 0 \\
\hline Chung et al., 2008 & 163 & Both & 60 & $3.6,{ }^{*} 1.2 \dagger$ \\
\hline \multirow[t]{2}{*}{ Cronqvist et al., 2005} & 14 & Ruptured & 71 & NA \\
\hline & 29 & UIA & 24 & $17.2,{ }^{*} 3.4 \dagger$ \\
\hline Grunwald et al., 2006 & 50 & UIA & 42 & 4 \\
\hline Hahnemann et al., 2014 & 75 & UIA & 64 & $6.7,{ }^{*} 1.3 \dagger$ \\
\hline Jo et al., 2013 & 282 & UIA & 31 & 1.8 \\
\hline Kang et al., $2013^{15}$ & 382 & UIA & 55 & 4.1 \\
\hline Kang et al., $2013^{14}$ & 40 & UIA & 60 & 0 \\
\hline Kim et al., $2013^{17}$ & 90 & UIA & 61 & 1.1 \\
\hline Lim Fat et al., 2013 & 135 & Both & 71 & NA \\
\hline Matsushige et al., 2013 & 34 & UIA & 77 & 0 \\
\hline Rordorf et al., 2001 & 14 & UIA & 64 & 7.1 \\
\hline Sim \& Shin, 2012 & 39 & Both & 44 & 10.3 \\
\hline Soeda et al., $2003^{33}$ & 66 & UIA & 61 & $22,{ }^{*} 5 \dagger$ \\
\hline Soeda et al., $2003^{32}$ & 26 & UIA & 69 & $27,{ }^{*} 0 \dagger$ \\
\hline
\end{tabular}

NA $=$ not available.

* Transient deficit.

$\dagger$ Permanent deficit.

of disabling stroke. Fortunately, complications with severe clinical consequences are rare, and large numbers of cases are needed to compare clinical complication rates.

According to studies for evaluation of endovascular procedures, the detection of new lesions on diffusionweighted MRI is regarded as a surrogate parameter for assessment of the ischemic treatment risks, with the advantage that clinically silent lesions can also be detected.

Following reports about frequent detection of lesions on diffusion-weighted imaging (DWI) after $\mathrm{EC}^{1,3,5-8,11-}$ 15,17,21,22,29,31-33 (Table 1) and previous studies concerning lesions found on DWI after MC, ${ }^{18,19,23}$ we strove to analyze lesion patterns and lesion load for both modalities in a single-center, interdisciplinary setting. Therefore, we systematically assessed the occurrence of new lesions found on DWI after repair of UIA by MC or EC, with the aim to describe the frequency of specific lesion patterns and the implications for clinical practice.

\section{Methods}

\section{Inclusion and Exclusion Criteria}

Patients with UIA who were scheduled for MC or EC, and who underwent MRI including DWI sequences the day before and the day after treatment, were prospectively included in this study.

The decision for MC or EC was made by consensus between vascular neurosurgeons and endovascular interventionalists, also considering the patient's preferences. The decision was based on aneurysm parameters (site, size, configuration, calcifications, and thrombosis) assessed on digital subtraction angiography (DSA) as well as on char- acteristics of the patient (age, comorbidities, and preference of the patient). The study was approved by the local review board. In addition, this study was registered with the ClinicalTrials.gov database (http://clinicaltrials.gov), and its registration no. is NCT01490463.

Patients were excluded from the study in any of the following conditions: 1) MRI contraindications, patient's refusal of MRI, or other reasons for missing the MRI within the appropriate time frame; 2) a history of previous aneurysmal hemorrhage; 3) aneurysms $>15 \mathrm{~mm}$; 4) previous treatment of the same aneurysm; 5) use of flow diverters; 6) simultaneous treatment of more than 1 aneurysm; or 7) temporary rapid ventricular pacing during $\mathrm{MC}$.

\section{Microsurgical Treatment}

A pterional craniotomy was used as the standard approach for all aneurysms of the anterior circulation or posterior communicating artery (PCoA). Clipping was performed in a standardized microsurgical procedure, opening the sylvian fissure and basal cisterns. In the patient with a posterior inferior cerebellar artery (PICA) aneurysm, a lateral suboccipital approach was used. The patients were kept normovolemic, with a mean arterial pressure of $80-100 \mathrm{~mm} \mathrm{Hg}$. Intraoperative monitoring was used routinely, measuring somatosensory and motor evoked potentials. ${ }^{34}$ Intraoperatively, indocyanine green video angiography was used in all procedures to verify aneurysm occlusion as well as parent vessel perfusion after clipping. ${ }^{27}$ Because we do not perform intraoperative angiography, all patients underwent postoperative DSA approximately 7 days after the procedure. 


\section{Endovascular Treatment}

Endovascular coiling was performed under general anesthesia via transfemoral placement of a 5-Fr or 6-Fr guiding catheter. For access to the anterior communicating artery $(\mathrm{ACoA})$ or other difficult approaches, a coaxial access system with a long carotid sheath and an inner guiding or distal access catheter were used. For superselective catheterization of aneurysms, we preferred a 0.010 -in microcatheter-microguidewire combination. For balloon- or stent-assisted coiling, we placed a second or larger guiding catheter and used compliant remodeling balloons or self-expanding microstents. Peri-interventional antithrombotic treatment was administered with a bolus of $5000 \mathrm{IU}$ of heparin and additional heparin (1000 $\mathrm{IU} / \mathrm{L})$ in flushing solutions. Aspirin $(100 \mathrm{mg})$ was started the day before intervention and continued for at least 3 months. Patients with wide-necked aneurysms or candidates for stent placement received double antiplatelet therapy, adding $75 \mathrm{mg}$ of clopidogrel for a minimum of 3 months.

\section{Examinations by MRI}

Magnetic resonance imaging of the brain was performed on a 3-T whole-body system (Magnetom Verio; Siemens) with an 8-channel phased-array head coil. The protocol included axial T2-weighted images, axial T2weighted FLAIR images, and axial and coronal singleshot echo-planar DWI (b 1000) with apparent diffusion coefficient maps.

All images were evaluated for consensus by a neuroradiologist (M.W.) and a neurosurgeon (J.P.).

\section{Primary End Point}

All patients underwent DWI prior to aneurysm repair but after initial DSA. The occurrence of new lesions as detected by DWI on the day after aneurysm treatment was the primary end point; thus lesions on DWI related to DSA prior to aneurysm repair were excluded. Therefore, this MRI (DWI) was compared with the MRI before treatment. For statistical analysis, the lesions detected by DWI were categorized as the following types: A) 1-3 DWI spots $<10 \mathrm{~mm}, \mathrm{~B})>3$ DWI spots $<10 \mathrm{~mm}, \mathrm{C}$ ) single DWI lesion $>10 \mathrm{~mm}$, or D) DWI lesion related to surgical access, which typically were small cortical lesions around the sylvian fissure and did not represent a typical vascular pattern after aneurysm securing (Fig. 1). These categories were based on previous reports of lesions detected by DWI $7,11,12,14,21,29,31,33$

\section{Statistical Analysis}

Continuous variables were compared using the MannWhitney U-test and categorical variables were analyzed using the chi-square or Fisher's exact test as appropriate. A $\mathrm{p}$ value $<0.05$ was considered significant. We used standard commercial software (SPSS Statistics version 21; IBM Corp.).

\section{Results}

During the treatment period, 237 UIA (205 patients)
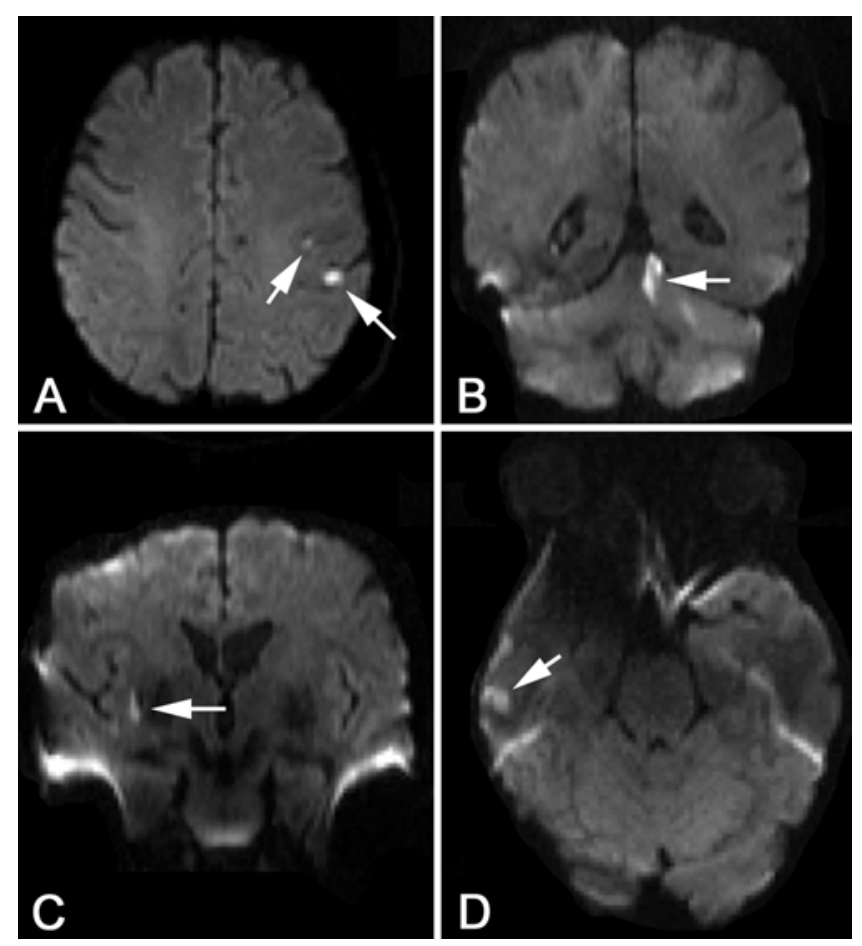

FIG. 1. Classification of DWI-detected lesions. Example for DWI spots < $10 \mathrm{~mm}$ (A) after EC of an MCA aneurysm (other lesions not shown; 6 total). Example for a single DWl-detected lesion $>10 \mathrm{~mm}$ (B) after EC of a basilar trunk aneurysm and (C) after MC of an MCA aneurysm. Example for a DWI-detected lesion related to surgical access (D) after MC of an ophthalmic artery aneurysm. White arrows denote DWI lesions.

were treated at our institution. The inclusion criteria were met by 99 UIA in 89 patients (Fig. 2). Microsurgical clipping was performed in 62 UIA and EC in 37. The demographic parameters were equally distributed between groups. The most striking difference between groups was distribution of the UIA (Table 2): 58 (93.5\%) aneurysms in the MC group were located in the anterior circulation, whereas $20(54.1 \%)$ aneurysms treated by EC were located in the posterior circulation $(\mathrm{p}<0.001)$.

Prior to aneurysm treatment, most patients showed no lesions on DWI (56 of 62 in the MC and 34 of 37 in the EC group; $\mathrm{p}=0.793)$. For A (1-3 DWI spots $<10 \mathrm{~mm}$ ), there were 3 patients $(4.8 \%)$ in the MC and $2(5.4 \%)$ in the EC group. For B ( $>3$ DWI spots $<10 \mathrm{~mm})$, there was $1(1.6 \%)$ case in the MC group and none in the EC group, whereas for $\mathrm{C}$ (single DWI lesion $>10 \mathrm{~mm}$ ), there were $2(3.2 \%)$ and $1(2.7 \%)$ case in the MC and EC groups, respectively $(\mathrm{p}=0.888)$. In 3 patients, the lesions detected by DWI were probably related to a previous angiogram. Microangiopathic genesis was suspected in another 3 patients, the etiology was uncertain in 2 patients, and the lesion in the remaining patient was related to a previous aneurysm treatment.

In the EC group, a stent was placed in 6 patients. The stent procedure was planned in 5 of these patients due to the wide neck of the aneurysm and was necessary in the last patient due to protrusion of a coil into the parent vessel. 


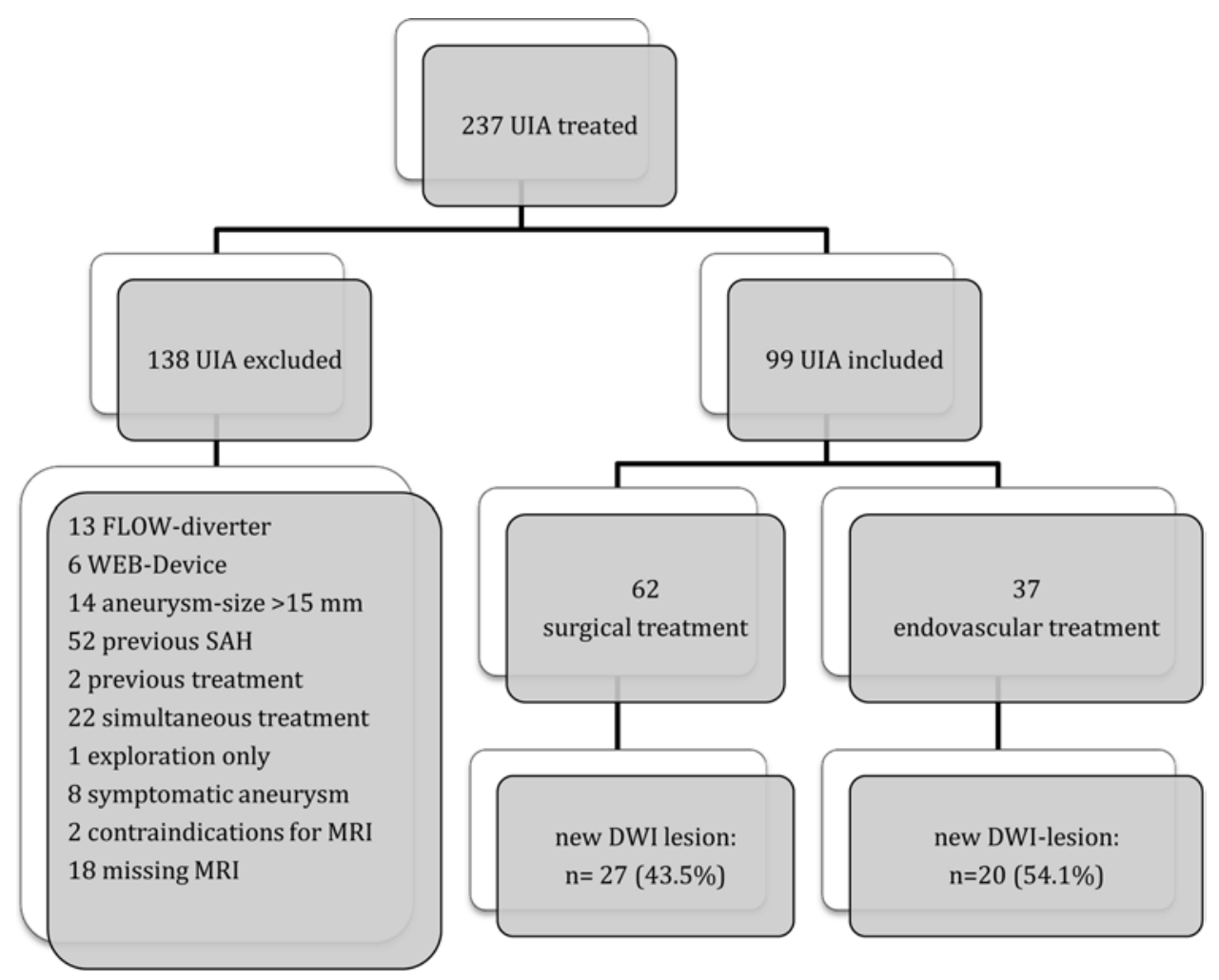

FIG. 2. Flow chart showing the included and excluded cases. The occurrence of new DWI-detected lesions was not statistically significantly different $(p=0.311)$. SAH = subarachnoid hemorrhage; $W E B=$ Woven EndoBridge device.

TABLE 2. Demographic parameters of patients and distribution of the aneurysms treated by MC and EC

\begin{tabular}{lccr}
\hline \multicolumn{1}{c}{ Parameter } & Endovascular & Surgical & p Value \\
\hline No. of patients & 37 & 62 & \\
\hline Age in yrs, mean \pm SD & $52.2 \pm 8.8$ & $53.2 \pm 9.1$ & $0.570^{*}$ \\
\hline Female sex, no. (\%) & $33(89.2)$ & $49(79.0)$ & $0.195 \dagger$ \\
\hline Arterial hypertension, no. (\%) & $15(40.5)$ & $26(41.9)$ & $0.892 \dagger$ \\
\hline Diabetes mellitus, no. (\%) & $2(5.4)$ & $3(4.8)$ & $1.000 \ddagger$ \\
\hline Smoker, no. (\%) & $14(37.8)$ & $26(41.9)$ & $0.688 \dagger$ \\
\hline Aneurysm size in mm, mean & $7.4 \pm 2.5$ & $7.6 \pm 2.4$ & $0.695^{*}$ \\
$\quad \pm$ SD & & & \\
\hline Multiple aneurysms, no. (\%) & $14(37.8)$ & $22(35.5)$ & $0.814 \dagger$ \\
\hline Aneurysm site, no. & & & $<0.001 \ddagger$ \\
\hline ACoA/ACA & 6 & 9 & \\
\hline MCA & 2 & 38 & \\
\hline ICA & 9 & 11 & \\
\hline PCoA & 6 & 3 & \\
\hline BA incl PCA & 13 & 0 & \\
\hline VA/PICA & 1 & 1 & \\
\hline BA & & & \\
\hline
\end{tabular}

$\mathrm{BA}=$ basilar artery; incl = including; $\mathrm{PCA}=$ posterior cerebral artery; $\mathrm{VA}=$ vertebral artery.

* Mann-Whitney U-test.

$\dagger$ Chi-square test.

‡ Fisher's exact test.

\section{Occurrence of New Lesions as Detected by DWI}

Overall, 52 cases $(52.5 \%)$ showed no new lesions on DWI after aneurysm occlusion. Yet, new lesions were detected by DWI in 27 of 62 cases (43.5\%) after MC and in 20 of 37 cases (54.1\%) after EC. The occurrence of new lesions on DWI was not significantly different between the groups ( $\mathrm{p}=0.311$; Fig. 3 ).

After MC, the most commonly detected types were C (single DWI lesion $>10 \mathrm{~mm}$ [ $\mathrm{n}=12$ cases $]$ ), A (1-3 DWI spots $<10 \mathrm{~mm}[\mathrm{n}=5$ cases $]$ ), and $\mathrm{D}$ (typical access-related DWI lesions $[\mathrm{n}=10])$. Of the 12 patients with Type $C, 11$ lesions were $<20 \mathrm{~mm}$. Only 1 patient developed a lesion detected by DWI in the territory of an $\mathrm{M}_{2}$ branch after clipping of a complex $10-\mathrm{mm}$, partially calcified middle cerebral artery (MCA) aneurysm with a wide neck. Ten instances of Type D were detected after clipping: 2 of 9 were ACoA (22\%), 5 of 38 MCA (13\%), 2 of 11 internal carotid artery (ICA; 18\%), and 1 of 3 PCoA aneurysms (33\%). In 20 cases, temporary clipping was used during the procedure. Of those, no new lesions were detected by DWI in 12 (60\%) patients. The use of temporary clipping did not make a statistically significant difference in the occurrence of new lesions found on DWI $(\mathrm{p}=0.640)$.

After EC, Type A (1-3 DWI spots $<10 \mathrm{~mm}$ ) was detected in 14 patients, Type B ( $>3$ DWI spots $<10 \mathrm{~mm}$ ) in 5 patients (maximum 9 spots, mean 6.4 spots), and Type $\mathrm{C}$ (a single DWI lesion $>10 \mathrm{~mm}$ ) was visible in 1 patient with a basilar trunk aneurysm. In 2 of the 5 patients with Type B, a temporary thrombus formation was noted dur- 


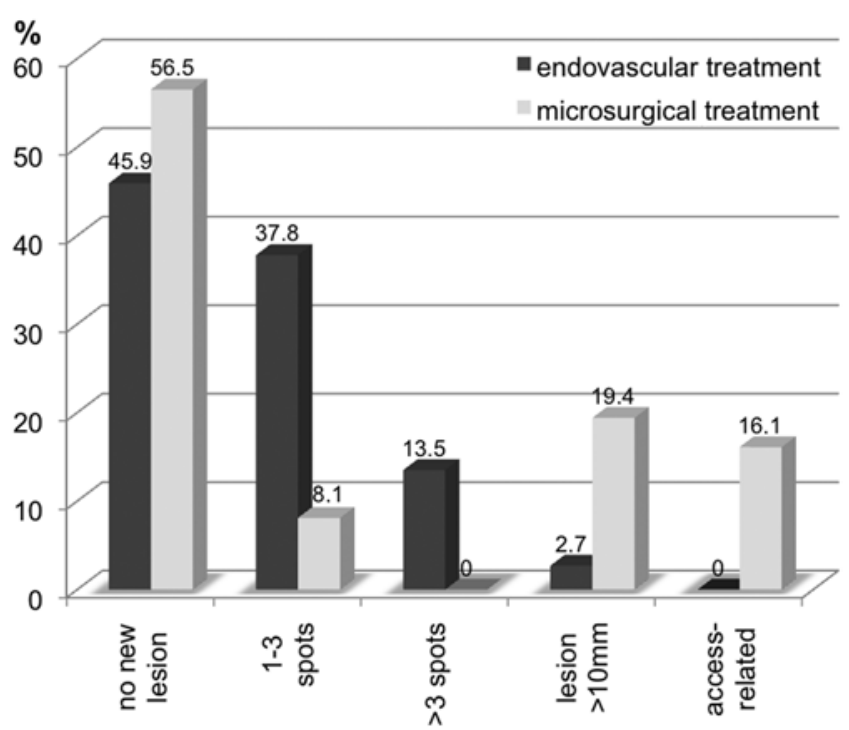

FIG. 3. Occurrence of new DWI-detected lesions after EC $(n=37)$ and $M C(n=62)$. The lesion distribution pattern was statistically significantly different between the 2 groups $(p<0.001)$.

ing the procedure and treated by intravenous tirofiban. Tirofiban was given to 1 more patient, who developed Type A. There was no association between aneurysm location and the detection of Type B (1 ophthalmic ICA, 2 basilar tip, $1 \mathrm{ACoA}$, and $1 \mathrm{MCA}$ aneurysm[s]). The use of the remodeling technique $(\mathrm{n}=6$; new lesions detected by DWI in $50 \%$ ) or a stent ( $\mathrm{n}=6$; new lesions detected by DWI in $66 \%$ was not statistically associated with the occurrence of new lesions on DWI $(\mathrm{p}=0.888)$.

The difference in the distribution pattern of the lesions detected by DWI between MC and EC was statistically significant $(\mathrm{p}<0.001)$. In almost all patients, the lesions detected by DWI were within the treated vascular territories. Only in 1 patient in the MC group and in 2 patients in the EC group was a different vascular territory affected $(\mathrm{p}=0.402)$.

\section{Risk Factors for the Occurrence of New Lesions as Detected by DWI}

As shown in Table 3, age, aneurysm size, female sex, history of arterial hypertension, diabetes mellitus, smoking, the occurrence of multiple aneurysms, site of the aneurysm, presence of lesions detected by DWI prior to aneurysm occlusion, or the method of aneurysm occlusion did not vary significantly between those patients with and without postprocedural lesions on DWI. Because we could not identify any significant difference for the occurrence of new lesions on DWI in the univariate analysis, we did not perform a multivariate analysis.

When the 2 groups were analyzed separately, we found more lesions on DWI in younger patients in the MC group $(\mathrm{p}=0.037$; Table 4), whereas this trend did not reach statistical significance in the EC group. No other parameters were statistically significant when each group was analyzed separately. Due to the limited numbers of aneurysms, statistical analysis of the influence of aneurysm
TABLE 3. Risk factors for the occurrence of new DWI-detected lesions after aneurysm occlusion

\begin{tabular}{lccc}
\hline \multicolumn{1}{c}{ Parameter } & $\begin{array}{c}\text { No New } \\
\text { Lesion, } \\
n=52\end{array}$ & $\begin{array}{c}\text { New } \\
\text { Lesion, } \\
\mathrm{n}=47\end{array}$ & $\begin{array}{c}\mathrm{p} \\
\text { Value }\end{array}$ \\
\hline Age in yrs, mean \pm SD & $53.8 \pm 8.9$ & $51.8 \pm 8.9$ & $0.476^{*}$ \\
\hline Aneurysm size in mm, mean \pm SD & $7.7 \pm 2.4$ & $7.3 \pm 2.4$ & $0.284^{*}$ \\
\hline Female sex, no. (\%) & $43(82.7)$ & $39(83.0)$ & $0.970 \dagger$ \\
\hline Arterial hypertension, no. (\%) & $20(38.5)$ & $21(44.7)$ & $0.530 \dagger$ \\
\hline Diabetes mellitus, no. (\%) & $1(1.9)$ & $4(8.5)$ & $0.187 \ddagger$ \\
\hline Smoker, no. (\%) & $21(40.4)$ & $19(40.4)$ & $0.997 \dagger$ \\
\hline Multiple aneurysms, no. (\%) & $15(28.8)$ & $21(44.7)$ & $0.102 \dagger$ \\
\hline Aneurysm site & & & $0.945 \ddagger$ \\
\hline ACoA/ACA & 7 & 8 & \\
\hline MCA & 21 & 19 & \\
\hline ICA & 11 & 9 & \\
\hline PCoA & 6 & 3 & \\
\hline BA/PCA & 6 & 7 & \\
\hline VA/PICA & 1 & 1 & \\
\hline No. of prior DWI-detected lesions & 4 & 5 & $0.611 \dagger$ \\
\hline Aneurysm treatment & & & $0.311 \dagger$ \\
\hline MC & 35 & 27 & \\
\hline EC & 17 & 20 & \\
\hline Man & & & \\
\hline
\end{tabular}

* Mann-Whitney U-test.

$\dagger$ Chi-square test.

$\ddagger$ Fisher's exact test.

location on the occurrence of new lesions detected by DWI is limited. The incidence of new lesions on DWI was higher after EC than after MC of ACoA/anterior cerebral artery (ACA) and MCA aneurysms.

\section{Clinical Outcome}

In both groups, most of the lesions detected by DWI were clinically silent. Clinical examinations after 6 months revealed no procedure-related unfavorable outcomes in either group, as judged by the modified Rankin Scale (mRS). Only 1 patient in each group had an mRS score between 3 and 6 , neither of which were related to the procedure (Table 5).

\section{Discussion}

The setting of this study was based on interdisciplinary consensus between neurosurgeons and neurointerventionalists regarding treatment of UIA by means of MC or EC. We could show that new post-therapeutic lesions were detected by DWI in both groups with similar frequencies but with different patterns. In the majority of cases, these lesions remained asymptomatic, whereas permanent neurological deficits are reported in the literature in approximately $4 \%$ of cases (range $0 \%-10 \%$; Table 1 ). To our knowledge, this is the first study to prospectively compare the occurrence of new lesions on DWI after an interdisciplinary consensus decision between vascular neuroin- 
TABLE 4. Occurrence of new DWI-detected lesions

\begin{tabular}{|c|c|c|c|c|c|c|}
\hline \multirow[b]{2}{*}{ Parameter } & \multicolumn{3}{|c|}{ Microsurgical Group, $n=62$} & \multicolumn{3}{|c|}{ Endovascular Group, $\mathrm{n}=37$} \\
\hline & No New Lesion, $n=35$ & New Lesion, $\mathrm{n}=27$ & $p$ Value & No New Lesion, $n=17$ & New Lesion, $n=20$ & p Value \\
\hline Age in yrs, mean \pm SD & $54.4 \pm 9.7$ & $51.8 \pm 8.3$ & $0.037^{*}$ & $52.5 \pm 7.4$ & $51.9 \pm 10.0$ & $0.328^{*}$ \\
\hline Aneurysm size in $\mathrm{mm}$, mean $\pm \mathrm{SD}$ & $7.9 \pm 2.5$ & $7.2 \pm 2.3$ & $0.692^{*}$ & $7.3 \pm 2.2$ & $7.4 \pm 2.7$ & $0.774^{*}$ \\
\hline Female sex, no. (\%) & $29(83)$ & $20(74)$ & $0.400 \dagger$ & $14(82)$ & $19(95)$ & $0.217 \dagger$ \\
\hline Multiple aneurysms, no. (\%) & $10(29)$ & $12(44)$ & $0.195 \dagger$ & $5(29)$ & $9(45)$ & $0.330 \dagger$ \\
\hline Aneurysm site, no. (\%) & & & $1.0 \ddagger$ & & & $0.651 \ddagger$ \\
\hline ACoA/ACA & & 4 of $9(44)$ & & & 4 of $6(67)$ & \\
\hline MCA & & 17 of $38(45)$ & & & 2 of $2(100)$ & \\
\hline ICA & & 5 of $11(45)$ & & & 4 of $9(44)$ & \\
\hline PCoA & & 1 of $3(33)$ & & & 2 of $6(33)$ & \\
\hline $\mathrm{BA} / \mathrm{PCA}$ & & 0 & & & 7 of $13(54)$ & \\
\hline VA/PICA & & 0 of $1(0)$ & & & 1 of $1(100)$ & \\
\hline No. of prior DWI lesions & 2 & 4 & $0.390 \ddagger$ & 2 & 1 & $0.584 \ddagger$ \\
\hline
\end{tabular}

* Mann-Whitney U-test.

† Chi-square test.

$\ddagger$ Fisher's exact test.

terventionalists and neurosurgeons has been made on the preferred aneurysm treatment. Furthermore, we believe that this study represents the largest number of patients observed after neurosurgical aneurysm repair with respect to this topic.

In this study, the distribution of lesions detected by DWI varied significantly between groups, with Types D (accessrelated DWI lesions) and C (single DWI lesion $>10 \mathrm{~mm}$ ) representing the most frequent lesions in the MC group, whereas microembolic spots found on DWI were the predominant lesions in the EC group. For the average patient with new lesions found on DWI, the lesion load was low and clearly below the level of a major branch occlusion.

For EC, this phenomenon is well known from previous studies, which show incidences of new lesions on DWI of between $10 \%$ and $77 \%$ (Table 1). ${ }^{13,5-8,11-15,17,21,22,29,31-33}$ For the etiology of these DWI-detected lesions, several explanations have been discussed. They may be due to thrombus formation at the catheter or guidewire, microemboli created by packing the aneurysmal sac densely with coils, thrombosis within the aneurysmal sac, or dislocation of coils protruding into the parent vessel. Furthermore, friable arteriosclerotic plaques and iatrogenic dissection of

\section{TABLE 5. Outcome after 6 months according to the mRS}

\begin{tabular}{|c|c|c|c|}
\hline $\begin{array}{l}\text { Outcome After } 6 \text { Mos } \\
\text { (mRS score) }\end{array}$ & $\begin{array}{c}\text { Endovascular, } \\
\text { No. }(\%)\end{array}$ & $\begin{array}{l}\text { Surgical, } \\
\text { No. (\%) }\end{array}$ & $\mathrm{p}$ Value \\
\hline Favorable (0-2) & $36(97.3)$ & $60(98.4)$ & $N S^{*}$ \\
\hline Unfavorable (3-6) & $1(2.7) \dagger$ & $1(1.6) \ddagger$ & \\
\hline \multicolumn{4}{|c|}{$\begin{array}{l}\text { NS = not significant. } \\
\text { * Fisher's exact test. } \\
\text { † One patient died within } 6 \text { months after treatment due to an underlying } \\
\text { disease (Creutzfeldt-Jakob). } \\
\text { ‡ One patient had an mRS score of } 3 \text { before treatment due to blindness and } \\
\text { remained unchanged post-treatment; } 1 \text { patient was lost to follow-up. }\end{array}$} \\
\hline
\end{tabular}

the parent vessel are possible mechanisms, as is the formation of air bubbles during contrast injection or during the introduction and placement of coils and other materials. ${ }^{11,17,26,29,32,33}$ Some studies suggested that the use of the remodeling technique, older patients, or larger aneurysm size are risk factors, whereas others did not.

Manipulations during the arterial access and in the parent vessel might explain the occurrence of DWI-detected lesions proximal to the treated UIA or lesions in other vascular territories than that of the treated aneurysm. ${ }^{31,32}$ Even after diagnostic angiography alone, new silent lesions were detected by DWI in $26 \%$ of patients. ${ }^{2}$ Lesions found on DWI after EC may be reversible, because permanent corresponding lesions were found much less frequently on T2-weighted images of follow-up MRI examinations..$^{2,7,22}$

Clinically, most of the lesions detected after EC are silent. They may become symptomatic, e.g., in cases with an unfavorable location in highly eloquent brain areas or if showers of multiple microemboli occur. Whether microembolic lesions found on DWI may cause neuropsychological deficits is a matter of controversy. ${ }^{14,35}$ A DWI substudy of the International Carotid Stenting Study found a significant incidence of new DWI-detected lesions even in extracranial procedures, but no clear neuropsychological correlate of these lesions. ${ }^{4}$

In our study, microembolic lesions detected by DWI after EC occurred despite a relatively aggressive antithrombotic regimen, with regular use of antiplatelet agents, heparin, and heparinized flushing solutions. Today, there is no proof that peri-interventional lesions can be avoided. With an average of 2.5 lesions per case, the lesion load was quite low, and it seems unlikely that neuropsychological changes are caused by single white matter lesions.

For MC, there are very few data on the occurrence of DWI-detected lesions. There are only 2 limited series that routinely assessed postprocedural lesions found on DWI, reporting $7.7 \%-13.9 \%$ new lesions after DWI, with only 
$0 \%-2.8 \%$ being symptomatic. ${ }^{18,19,23}$ Krayenbühl et al. reported the same series of 36 patients twice with a different focus, ${ }^{18,19}$ whereas Murai et al. focused on MCA aneurysms only $(n=42) .{ }^{23}$ Both studies included ruptured and unruptured aneurysms. Because the focus of each study was slightly different, we do not know whether the authors took access-related lesions into account. Murai et al. reported a surprisingly low complication rate compared with randomized controlled trials. ${ }^{23}$ In general, ischemic complications based on imaging or clinical symptoms are detected in $2.6 \%-12.1 \%$ of patients after MC treatment of UIA. 10,16,20,25,36,37 Only 1 of these studies used postprocedural MRI; however, in this study, only symptomatic patients or patients with intraoperative complications underwent MRI. ${ }^{20}$ Therefore, the rate of silent DWI-detected lesions is probably underrepresented or unknown in all previous studies.

In regard to the small cortical lesions around the sylvian fissure, Ngando et al. suggested that with increasing complexity and invagination of the sylvian fissure, postoperative brain edema and ischemia ${ }^{24}$ may occur as the result of microsurgical splitting, despite the avoidance of extensive manipulation of the vessels within the fissure as well as the use of retractor systems. Because these techniques are used not only for clipping of aneurysms but in many neurosurgical procedures, the impact of these lesions on the outcomes of patients seems negligible, because usually they do not correlate with neurological deterioration postoperatively.

Apart from lesions due to surgical access, the most common lesions found on DWI were Type C (single DWI lesion $>10 \mathrm{~mm}$ ). The DWI-detected lesion pattern suggests occlusion of small perforators as the most probable cause of these lesions, which were predominantly detected after MC of aneurysms at bifurcations and a significant number of perforators such as MCA bifurcation aneurysms. In MCA aneurysms, MC is generally preferred to EC due to the complex anatomical features, including a wide neck, incorporation of 1 or more $\mathrm{M}_{2}$ branches into the aneurysm's neck, and the origin of perforators. ${ }^{9,16,28}$ In a CT-based study, infarctions were detected in $26 \%$ of cases after MC of MCA aneurysms, and the authors concluded that the high density of perforators in MCA aneurysms represents a special risk. ${ }^{30}$ Atherosclerotic changes and neck calcification may be associated with higher risks of branch occlusions at the MCA bifurcation. ${ }^{34}$ Direct manipulation of tiny vessels may also cause DWI-detected lesions. In this study, with 1 exception, the lesion size did not exceed a maximal diameter of $20 \mathrm{~mm}$. None of these lesions was associated with an unfavorable outcome.

\section{Limitations of the Study}

First, the number of patients is limited in this study, although to our knowledge it is the largest study to assess the occurrence of new DWI-detected lesions after MC and EC. In addition, there is asymmetry between treatment arms, with 62 UIA treated by MC and only 37 by EC. This may be related to a trend at our institution to favor $\mathrm{MC}$ over EC, especially in younger patients, to achieve a better long-term outcome and to avoid further controls by follow-up imaging. Furthermore, this study was not a randomized controlled trial but was focused to achieve the best treatment for each case, as judged by an interdisciplinary consensus based on the International Study of Unruptured Intracranial Aneurysms criteria. ${ }^{36}$ Thus, this study loses some power due to the unbalanced numbers between groups, while it gains strength because it reflects the daily practice in most modern neurovascular centers.

The different patterns and mechanisms of lesions found on DWI after EC and MC make comparison between the 2 groups difficult. This is reflected by the categories we used to describe the DWI-detected lesions, which might fit better for some of the lesions than for others. Because most previous reports have focused on endovascular aneurysm treatment, the categories we used were based predominantly on embolic lesions. Although the nature of lesions found on DWI after MC might differ and, for example, perforator lesions might occur more frequently, these lesions are often small too, and their clinical impact varies significantly with the location of the lesion.

Furthermore, many patients were not included in the study due to the relatively strict inclusion criteria, which led to exclusion of many cases in which more complex techniques were used. This may have caused a bias toward standard cases with lower treatment risks for both modalities.

Because there are various studies that have reported the impact of silent DWI-detected lesions on the neuropsychological outcomes of the patients, thorough neuropsychological testing of the patients before and after treatment would have been warranted.

\section{Perspectives on the Study Results}

Similar to the results of other studies, DWI has shown its potential to detect the integrity of the brain parenchyma after microsurgical or endovascular procedures, although the impact of these lesions on clinical outcomes is not clear. This study confirmed that even subtle and subclinical lesions can be detected, which may correlate with the risk of embolism or branch occlusion. For EC, the avoidance of thromboembolism by antithrombotic medication and testing for aspirin or clopidogrel resistance may lower the rate of microemboli. Further efforts should be made to avoid injection or infusion of micro-air bubbles during catheterization or introduction of implants. For surgical cases, we try to avoid clipping of aneurysms with heavily calcified necks and to apply new techniques to increase safety for the patient.

Further studies with less-rigid exclusion criteria may underline the role of DWI as a means of quality control. A study with a larger number of cases may contribute to defining risk groups and to changing treatment assignment in cases with increased endovascular or surgical risks.

\section{Conclusions}

Lesions detected by DWI occur with similar frequencies after MC or EC of UIA. The lesion patterns are significantly different, with a predominance of microembolic lesions after EC and lesions due to surgical access or small branch occlusions after MC. In general, the lesion load was low in both arms, and most of the lesions remained clini- 
cally silent. Further DWI studies are warranted to define risk groups and to increase the safety of UIA treatment.

\section{Acknowledgments}

This study was funded by the institutional resources of the Johann Wolfgang Goethe-University, Frankfurt.

\section{References}

1. Altay T, Kang HI, Woo HH, Masaryk TJ, Rasmussen PA, Fiorella DJ, et al: Thromboembolic events associated with endovascular treatment of cerebral aneurysms. J Neurointerv Surg 3:147-150, 2011

2. Bendszus M, Koltzenburg M, Burger R, Warmuth-Metz M, Hofmann E, Solymosi L: Silent embolism in diagnostic cerebral angiography and neurointerventional procedures: a prospective study. Lancet 354:1594-1597, 1999

3. Biondi A, Oppenheim C, Vivas E, Casasco A, Lalam T, Sourour N, et al: Cerebral aneurysms treated by Guglielmi detachable coils: evaluation with diffusion-weighted MR imaging. AJNR Am J Neuroradiol 21:957-963, 2000

4. Bonati LH, Jongen LM, Haller S, Flach HZ, Dobson J, Nederkoorn PJ, et al: New ischaemic brain lesions on MRI after stenting or endarterectomy for symptomatic carotid stenosis: a substudy of the International Carotid Stenting Study (ICSS). Lancet Neurol 9:353-362, 2010 (Erratum in Lancet Neurol 9:345, 2010)

5. Bracard S, Abdel-Kerim A, Thuillier L, Klein O, Anxionnat R, Finitsis S, et al: Endovascular coil occlusion of 152 middle cerebral artery aneurysms: initial and midterm angiographic and clinical results. J Neurosurg 112:703-708, 2010

6. Chung SW, Baik SK, Kim Y, Park J: Thromboembolic events after coil embolization of cerebral aneurysms: prospective study with diffusion-weighted magnetic resonance imaging follow-up. J Korean Neurosurg Soc 43:275-280, 2008

7. Cronqvist M, Wirestam R, Ramgren B, Brandt L, Nilsson O, Säveland H, et al: Diffusion and perfusion MRI in patients with ruptured and unruptured intracranial aneurysms treated by endovascular coiling: complications, procedural results, MR findings and clinical outcome. Neuroradiology 47:855873,2005

8. Derdeyn CP, Cross DT III, Moran CJ, Brown GW, Pilgram TK, Diringer MN, et al: Postprocedure ischemic events after treatment of intracranial aneurysms with Guglielmi detachable coils. J Neurosurg 96:837-843, 2002

9. Diaz OM, Rangel-Castilla L, Barber S, Mayo RC, Klucznik R, Zhang YJ: Middle cerebral artery aneurysms: a singlecenter series comparing endovascular and surgical treatment. World Neurosurg 81:322-329, 2014

10. Gerlach R, Beck J, Setzer M, Vatter H, Berkefeld J, Du Mesnil de Rochemont R, et al: Treatment related morbidity of unruptured intracranial aneurysms: results of a prospective single centre series with an interdisciplinary approach over a 6 year period (1999-2005). J Neurol Neurosurg Psychiatry 78:864-871, 2007

11. Grunwald IQ, Papanagiotou P, Politi M, Struffert T, Roth C, Reith W: Endovascular treatment of unruptured intracranial aneurysms: occurrence of thromboembolic events. Neurosurgery 58:612-618, 2006

12. Hahnemann ML, Ringelstein A, Sandalcioglu IE, Goericke S, Moenninghoff C, Wanke I, et al: Silent embolism after stent-assisted coiling of cerebral aneurysms: diffusionweighted MRI study of 75 cases. J Neurointerv Surg 6:461465, 2014

13. Jo KI, Yeon JY, Kim KH, Jeon P, Kim JS, Hong SC: Predictors of thromboembolism during coil embolization in patients with unruptured intracranial aneurysm. Acta Neurochir (Wien) 155:1101-1106, 2013
14. Kang DH, Hwang YH, Kim YS, Bae GY, Lee SJ: Cognitive outcome and clinically silent thromboembolic events after coiling of asymptomatic unruptured intracranial aneurysms. Neurosurgery 72:638-645, 2013

15. Kang DH, Kim BM, Kim DJ, Suh SH, Kim DI, Kim YS, et al: MR-DWI-positive lesions and symptomatic ischemic complications after coiling of unruptured intracranial aneurysms. Stroke 44:789-791, 2013

16. Kim KH, Cha KC, Kim JS, Hong SC: Endovascular coiling of middle cerebral artery aneurysms as an alternative to surgical clipping. J Clin Neurosci 20:520-522, 2013

17. Kim MJ, Lim YC, Oh SY, Kim BM, Kim BS, Shin YS: Thromboembolic events associated with electrolytic detachment of Guglielmi detachable coils and target coils: comparison with use of diffusion-weighted MR imaging. J Korean Neurosurg Soc 54:19-24, 2013

18. Krayenbühl N, Erdem E, Oinas M, Krisht AF: Symptomatic and silent ischemia associated with microsurgical clipping of intracranial aneurysms: evaluation with diffusion-weighted MRI. Stroke 40:129-133, 2009

19. Krayenbühl N, Sarnthein J, Oinas M, Erdem E, Krisht AF: MRI-validation of SEP monitoring for ischemic events during microsurgical clipping of intracranial aneurysms. Clin Neurophysiol 122:1878-1882, 2011

20. Kunz M, Bakhshai Y, Zausinger S, Fesl G, Janssen H, Brückmann $\mathrm{H}$, et al: Interdisciplinary treatment of unruptured intracranial aneurysms: impact of intraprocedural rupture and ischemia in 563 aneurysms. J Neurol 260:1304-1313, 2013

21. Lim Fat MJ, Al-Hazzaa M, Bussière M, dos Santos MP, Lesiuk $\mathrm{H}$, Lum C: Heparin dosing is associated with diffusion weighted imaging lesion load following aneurysm coiling. J Neurointerv Surg 5:366-370, 2013

22. Matsushige T, Kiura Y, Sakamoto S, Okazaki T, Shinagawa $\mathrm{K}$, Ichinose N, et al: Multiple antiplatelet therapy contributes to the reversible high signal spots on diffusion-weighted imaging in elective coiling of unruptured cerebral aneurysm. Neuroradiology 55:449-457, 2013

23. Murai Y, Adachi K, Matano F, Takagi R, Amano Y, Kobayashi $\mathrm{S}$, et al: 3.0-T diffusion images after clipping of middle cerebral artery aneurysm. Turk Neurosurg 23:772-777, 2013

24. Ngando HM, Maslehaty H, Schreiber L, Blaeser K, Scholz M, Petridis AK: Anatomical configuration of the Sylvian fissure and its influence on outcome after pterional approach for microsurgical aneurysm clipping. Surg Neurol Int 4:129, 2013

25. Niskanen M, Koivisto T, Rinne J, Ronkainen A, Pirskanen $\mathrm{S}$, Saari T, et al: Complications and postoperative care in patients undergoing treatment for unruptured intracranial aneurysms. J Neurosurg Anesthesiol 17:100-105, 2005

26. Qureshi AI, Luft AR, Sharma M, Guterman LR, Hopkins LN: Prevention and treatment of thromboembolic and ischemic complications associated with endovascular procedures: Part I-Pathophysiological and pharmacological features. Neurosurgery 46:1344-1359, 2000

27. Raabe A, Nakaji P, Beck J, Kim LJ, Hsu FP, Kamerman JD, et al: Prospective evaluation of surgical microscopeintegrated intraoperative near-infrared indocyanine green videoangiography during aneurysm surgery. J Neurosurg 103:982-989, 2005

28. Rodríguez-Hernández A, Sughrue ME, Akhavan S, Habdank-Kolaczkowski J, Lawton MT: Current management of middle cerebral artery aneurysms: surgical results with a "clip first" policy. Neurosurgery 72:415-427, 2013

29. Rordorf G, Bellon RJ, Budzik RE Jr, Farkas J, Reinking GF, Pergolizzi RS, et al: Silent thromboembolic events associated with the treatment of unruptured cerebral aneurysms by use of Guglielmi detachable coils: prospective study applying diffusion-weighted imaging. AJNR Am J Neuroradiol 22:5-10, 2001 
30. Samson D, Batjer HH, Bowman G, Mootz L, Krippner WJ Jr, Meyer YJ, et al: A clinical study of the parameters and effects of temporary arterial occlusion in the management of intracranial aneurysms. Neurosurgery 34:22-29, 1994

31. Sim SY, Shin YS: Silent microembolism on diffusionweighted MRI after coil embolization of cerebral aneurysms. Neurointervention 7:77-84, 2012

32. Soeda A, Sakai N, Murao K, Sakai H, Ihara K, Yamada N, et al: Thromboembolic events associated with Guglielmi detachable coil embolization with use of diffusion-weighted MR imaging. Part II. Detection of the microemboli proximal to cerebral aneurysm. AJNR Am J Neuroradiol 24:20352038, 2003

33. Soeda A, Sakai N, Sakai H, Iihara K, Yamada N, Imakita S, et al: Thromboembolic events associated with Guglielmi detachable coil embolization of asymptomatic cerebral aneurysms: evaluation of 66 consecutive cases with use of diffusion-weighted MR imaging. AJNR Am J Neuroradiol 24:127-132, 2003

34. Szelényi A, Beck J, Strametz R, Blasel S, Oszvald A, Raabe A, et al: Is the surgical repair of unruptured atherosclerotic aneurysms at a higher risk of intraoperative ischemia? Clin Neurol Neurosurg 113:129-135, 2011

35. Vermeer SE, Longstreth WT Jr, Koudstaal PJ: Silent brain infarcts: a systematic review. Lancet Neurol 6:611-619, 2007

36. Wiebers DO, Whisnant JP, Huston J III, Meissner I, Brown RD Jr, Piepgras DG, et al: Unruptured intracranial aneurysms: natural history, clinical outcome, and risks of surgical and endovascular treatment. Lancet 362:103-110, 2003
37. Zijlstra IA, Verbaan D, Majoie CB, Vandertop P, van den Berg R: Coiling and clipping of middle cerebral artery aneurysms: a systematic review on clinical and imaging outcome. J Neurointerv Surg 8:24-29, 2016

\section{Disclosures}

The authors report no conflict of interest concerning the materials or methods used in this study or the findings specified in this paper.

\section{Author Contributions}

Conception and design: Platz, Güresir, Berkefeld, Seifert. Acquisition of data: Platz, Wagner, Güresir, You, Konczalla, du Mesnil de Rochemont. Analysis and interpretation of data: Platz, Wagner, Berkefeld, Seifert. Drafting the article: Platz, Wagner. Critically revising the article: Güresir, du Mesnil de Rochemont, Berkefeld, Seifert. Reviewed submitted version of manuscript: Platz, Wagner, Berkefeld, Seifert. Approved the final version of the manuscript on behalf of all authors: Platz. Statistical analysis: Platz. Study supervision: Berkefeld, Seifert.

\section{Correspondence}

Johannes Platz, Department of Neurosurgery, University Hospital Frankfurt, Goethe-University, Schleusenweg 2-16, Frankfurt 60528, Germany. email: platz@med.uni-frankfurt.de. 